\title{
Analysis of the Legal Effect of Settlement Agreements Prepared in Medical Litigation Following Plastic Surgery in Korea
}

\author{
Jung Woo Kwon, Bo Young Park, So Ra Kang, Seung Eun Hong \\ Department of Plastic and Reconstructive Surgery, Ewha Womans University Mokdong Hospital, Seoul, Korea
}

Background Settlements between doctors and patients provide a solution to complicated disputes. However, some disputes may be renewed as a result of negligence by both parties. The purpose of this study was to review the legal issues that may potentially arise during the preparation of settlement agreements and to propose a list of requirements for ensuring the effectiveness of these settlement agreements.

Methods Data from 287 civil cases concerning aesthetic surgery that took place between 2000 and 2015 were collected from a court database in South Korea. Factors that influenced the effectiveness of settlement agreements were analyzed.

Results Among the 287 court precedents, there were 68 cases of covenant not to sue. Eighteen cases were dismissed because the settlement agreements were recognized as effective, and 50 cases were sent forward for judgment on their merits because the agreements were not recognized as effective. The types of surgery and types of complications were classified by frequency. We evaluated the geographical distribution of the precedents, the settlement timing, and the effectiveness and economic impact of the settlements. We found that there was no statistically significant relationship among these factors. Four major factors that made a settlement agreement legally effective were identified, and the data showed that fee-free reoperations were not considered by the court in determining the compensation amount.

Conclusions When preparing a settlement agreement, it is advisable to review the contents of the agreement rather than to take the preparation of a settlement agreement per se to be legally meaningful.

Keywords Medical malpractice claims / Cosmetic surgery / Settlement agreement
Correspondence: Seung Eun Hong Department of Plastic and Reconstructive Surgery, Ewha Womans University Mokdong Hospital, 1071 Anyangcheon-ro, Yangcheon-gu, Seoul 07985, Korea Tel: +82-2-2650-5149 Fax: +82-2-3410-0036 E-mail: monkeyhong@hanmail.net

Received: 17 Oct $2016 \bullet$ Revised: 11 May 2017 • Accepted: 7 Jun 2017

pISSN: 2234-6163 • elSSN: 2234-6171 • https://doi.org/10.5999/aps.2017.44.4.283・Arch Plast Surg 2017;44:283-292

We would like to sincerely and profusely thank all members of our staff at Ewha Womans University Mokdong Hospital for their ample guidance and support in completing this project.

No potential conflict of interest relevant to this article was reported.

\section{INTRODUCTION}

There is a proverb among Korean surgeons that says "no surgery, no complication." It means that some complications are inevitable despite the best effort of the physician. This proverb particularly applies to the field of plastic surgery in Korea, which has recently experienced an explosion in growth.

According to the International Society of Aesthetic Plastic Surgery's International Survey on Aesthetic/Cosmetic Procedures, there were 2,054 plastic surgeons in South Korea in 2014. 
Furthermore, 980,313 surgical and non-surgical procedures were performed in South Korea in the same year, corresponding to the fourth largest number of total procedures performed worldwide. In total, South Korea has the largest number of plastic surgeons and procedures performed worldwide [1].

Plastic surgery is a medical specialty that is at risk of substantially high malpractice claims [2]. The number of medical disputes inevitably grows as the number of procedures increases. Consequently, plastic surgeons in South Korea who may experience frequent medical disputes possess either personal insurance or insurance offered by the clinic.

\section{Definition of terms: "medical malpractice, medical dispute, medical litigation"}

Various terms must be defined first. "Medical malpractice" is defined as any act or error by a physician during the treatment of a patient that deviates from accepted norms of practice in the medical community and causes injury to the patient. Medical malpractice is adjudicated by the court or an official medical committee. A "medical dispute (argument)" is defined as a patient proposal in return for the argument (any form of request such as a threat, apology, or reimbursement), which may or may not correlate with medical malpractice. "Medical litigation" occurs when the patient files a lawsuit against the physician over a medical dispute [3].

In Korea, medical disputes are increasing by the day, and many disputes proceed to medical litigation when a realistic solution cannot be found during the dispute [4]. However, medical malpractice in plastic surgery is generally resolved through a smooth settlement between the patient and the physician, rather than through litigation or mediation [5]. Settlements are resolved similarly to the dispute resolution method and on a par with litigation such that they save costs and time; seek an amicable resolution; provide a solution for complicated disputes that are difficult to prove, like medical accidents; reduce the possibility of misjudgment; and reduce the emotional conflict between parties through mutual concessions. However, some disputes may be renewed as a result of negligence by both parties during the settlement process, even after resolving the dispute through an amicable settlement process, as shown in Fig. 1. In other words, notwithstanding the agreement not to sue, one party institutes litigation against the other party. An agreement not to sue is called a 'covenant not to sue, in which both parties agree to informally reach a settlement for a certain dispute and also agree not to initiate legal proceedings in the future. This covenant not to sue must be in writing [6] and must plainly express the parties' intentions not to sue one another [7]. If a settlement agreement is effectively executed, the initiation of litigation is a violation of the agreement on which the other party may assert its rights against the violation. However, if the settlement agreement is not effective, a more complicated situation arises.

The purpose of this study was to analyze the legal issues that may potentially arise during the preparation of a settlement agreement in the field of plastic surgery, where settlement agree-

\section{Fig. 1. Schema of medical dispute in South Korea}

Schema of the medical disputes resolving process in South Korea. N, no; $Y$, yes. a) Settlement include followings, free of charge compensation procedure such as surgery or minimally invasive procedures,

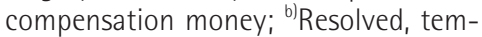
porary, the patient might be settled at first, however, the remaining dissatisfaction continues for him/her to accuse the medical disputes again. This usually goes up to the medical litigation.

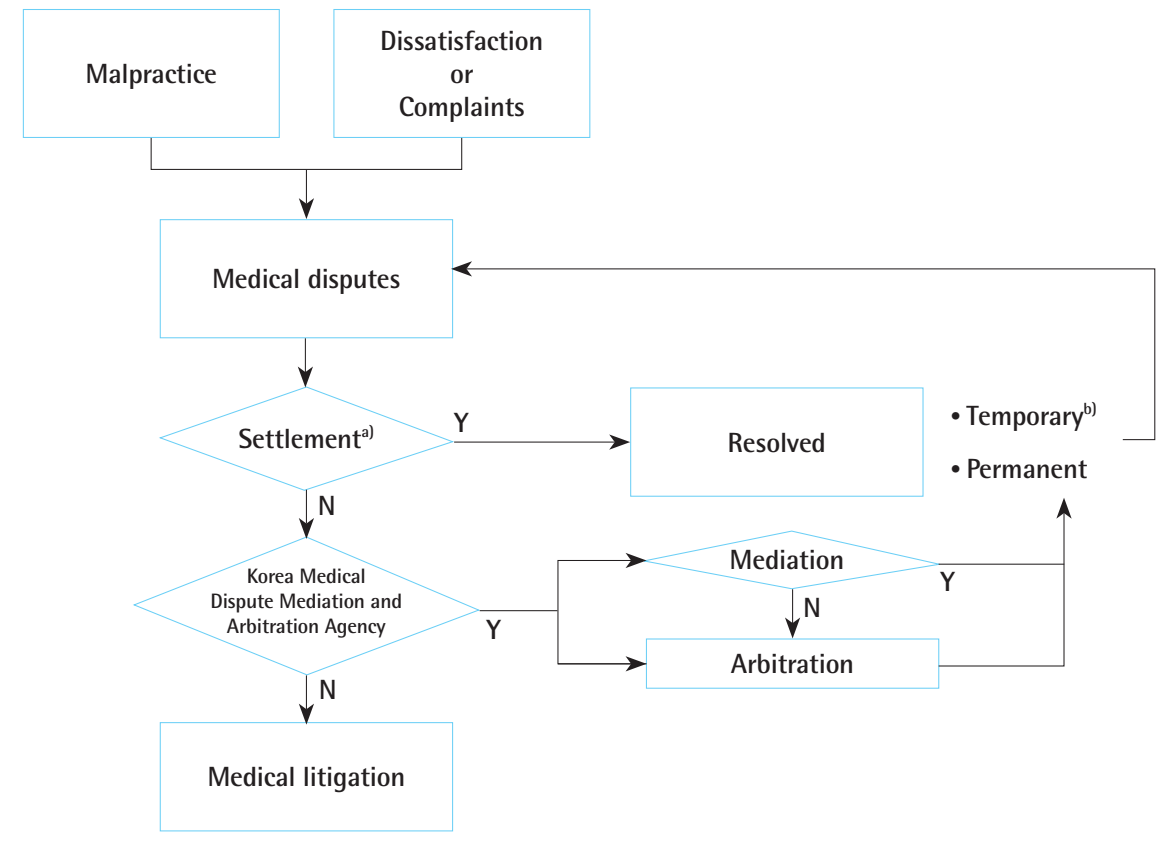




\section{Fig. 2. Study diagram, search terms, and results}

A total of 68 medical litigation cases regarding aesthetic procedures during the study period.

"Medical malpractice" and "Plastic surgery" OR "Aesthetic surgery" OR "Blepharoplasty" OR "Rhinoplasty" OR "Facial contour surgery" OR "Filler" OR "Laser" OR "Lifting" OR "Thread lift" OR "Mammoplasty" OR "Liposuction" OR "Fat injection" OR "Botox injection" OR "Two jaw surgery" OR "Face lift"

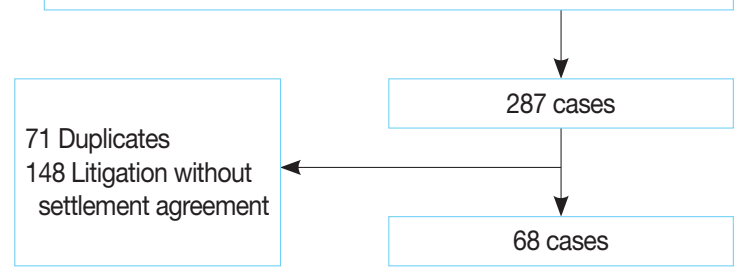

ments are frequently prepared. We also propose a set of requirements that should be met in order to effectively resolve disputes that may fall within the scope of court precedents concerning plastic surgery.

\section{METHODS}

The court precedents subject to this study were identified by typing the names of major plastic surgery procedures as keywords into the publicly accessible lower court decision database of South Korea (Fig. 2).

The data used as the source for this analysis were from district court precedents across the country that occurred between 2000 and 2015. These civil cases were related to cosmetic plastic surgery in which the patients and doctors had entered a covenant not to sue following a compensation procedure. We analyzed the raw data from 287 cases for the which entire legal proceedings were obtainable through a request for a written copy from the Supreme Court and the lower courts. We reviewed the types of surgical procedures, the complications that resulted in the dispute, whether the covenant not to sue was recognized by the court, and the criteria that were applied to recognize a covenant not to sue as effective. Furthermore, we reviewed the judgements of the court in cases where a covenant not to sue was not recognized.

\section{RESULTS}

\section{Case classification and distribution of complications}

Among the 287 court precedents, there were 68 cases of covenant not to sue between the patient and the doctor. The cases were classified by surgical procedure and included 23 cases of augmentation mammaplasty, 12 cases of facial contouring sur-

\section{Fig. 3. Classification by type of procedure}

There were 6 different types of procedures that were included in this study. (A) Augmentation mammaplasty: implants, fat graft. (B) Facial contouring surgery: two-jaw surgery, zygoma reduction, genioplasty. (C) Body contouring surgery: liposuction, abdominoplasty. (D) Facial rejuvenation: botulinum toxin injection, filler injection, face lift, thread lift. (E) Rhinoplasty: tip plasty, augmentation rhinoplasty, fat graft, dermofat graft. (F) Blepharoplasty: upper or lower blepharoplasty, double eyelidplasty, medial epicanthoplasty.

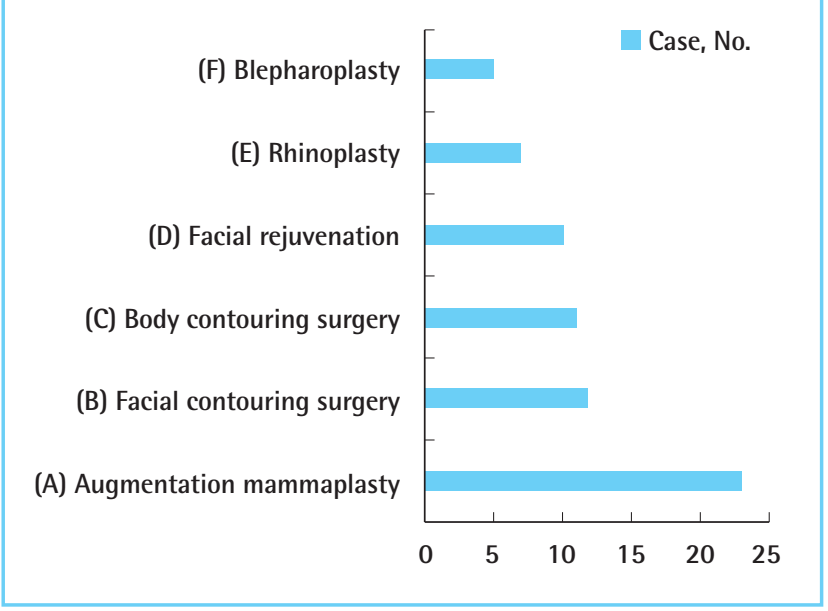

gery, 11 cases of body contouring surgery, 10 cases of facial rejuvenation, 7 cases of rhinoplasty, and 5 cases of blepharoplasty (Fig. 3).

The cases were also classified by complication and included 32 cases of deformity, 26 cases of sensory change, 17 cases of asymmetry, 15 cases of skin necrosis, 13 cases of infection, 5 cases of capsular contracture, 4 cases of motor nerve injury, 2 cases of non-union, 2 cases of implant deviation, and 1 case each of exposure keratitis, ectropion, lagophthalmos, and malocclusion (Fig. 4).

Eighteen cases were dismissed following a violation of a covenant not to sue because the settlement agreement between the patient and doctor was recognized as effective, and 50 cases were sent forward for judgment on their merits because the settlement agreement between the patient and doctor was not recognized as effective (Table 1 ).

\section{Geographical distribution of the precedents}

In Korea, the distribution of both the total population and plastic surgeons is highly concentrated in the Seoul metropolitan area (Fig. 5). Currently, 10 million people live in Seoul and 54\% of plastic surgeons work there. In our study, 42 cases occurred in Seoul, 12 of which had effective settlements and 30 of which had ineffective settlements. In addition, 12 million people live in Gyeonggi-do, the area surrounding the capital, yet only $12 \%$ of plastic surgeons work there. In our study, 16 cases occurred in Gyeonggi-do, 4 of which had effective settlements and 8 of 


\section{Fig. 4. Classification by complication and type of procedure}

Patients experienced 15 different types of complications in this study. The most frequent complication was deformity (32 cases), followed by sensory change ( 26 cases), and finally asymmetry (17 cases). The number of complications was more than the total number of litigation cases, as some patients suffered from 2 or more symptoms.

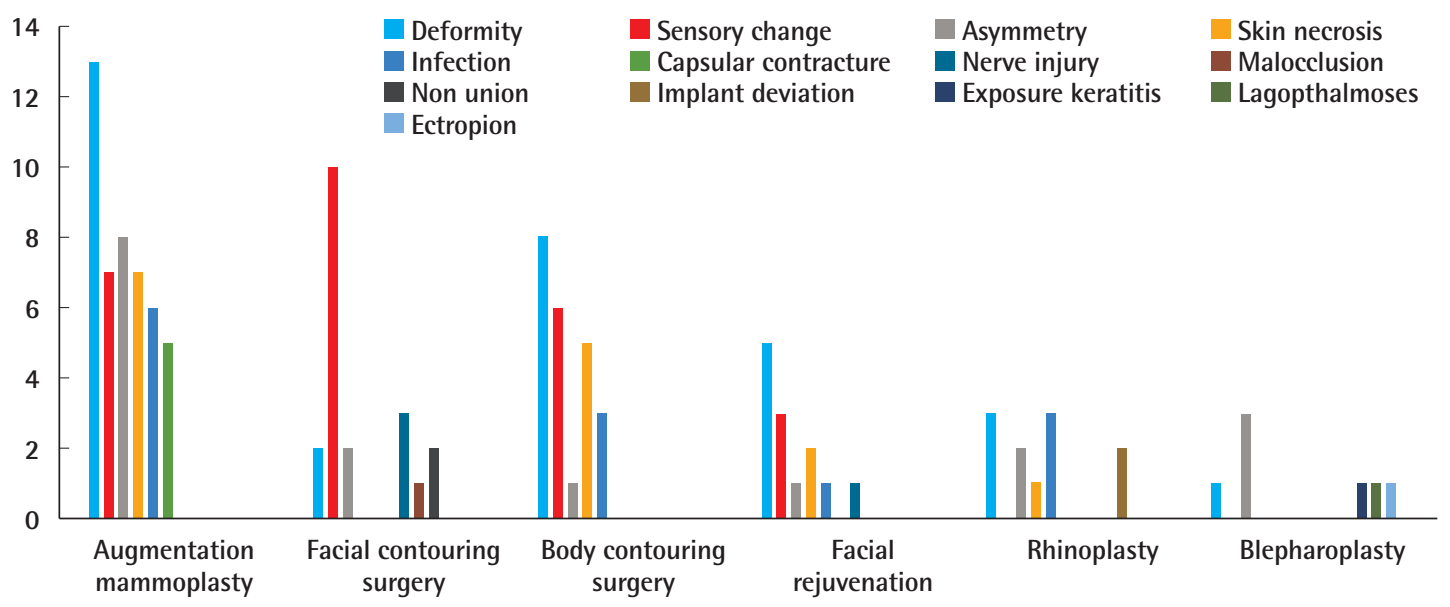

\section{Table 1. Court precedents in which the settlement between the patient and doctor was recognized as effective}

\begin{tabular}{|c|c|c|c|c|c|c|c|c|}
\hline Case & Procedure & Alleged & injury & Settlement & Legal force & Amount of claim ${ }^{\text {a) }}$ & $\begin{array}{l}\text { Judgement } \\
\text { amount (\$) }\end{array}$ & Judgement \\
\hline 1 & Augmentation rhinoplasty & Deformity & - & $Y$ & $Y$ & $16,700(20,000,000)$ & 0 & A \\
\hline 2 & Bleparoplasty & Ectropion & Pain & Y & Y & $26,320(31,519,000)$ & 0 & B \\
\hline 3 & Bleparoplasty & Skin necrosis & Deformity & Y & Y & $25,052(30,000,000)$ & 0 & A \\
\hline 4 & Augmentation rhinoplasty & Implant deviation & Deformity & Y & Y & $35,073(42,000,000)$ & 0 & A \\
\hline 5 & Augmentation rhinoplasty & Deformity & - & Y & Y & $23,382(28,000,000)$ & 0 & $A$ \\
\hline 6 & Augmentation rhinoplasty & Deformity & - & Y & Y & $43,423(52,000,000)$ & 0 & A \\
\hline 7 & Augmentation rhinoplasty & Implant deviation & Deformity & Y & Y & $33,402(40,000,000)$ & 0 & $A$ \\
\hline 8 & Bleparoplasty & Exposure ketatitits & Deformity & Y & Y & $42,588(51,000,000)$ & 0 & A \\
\hline 9 & Bleparoplasty & Lagophthalmose & Deformity & Y & Y & $14,196(17,000,000)$ & 0 & A \\
\hline 10 & Augmentation rhinoplasty & Deformity & - & Y & Y & $31,732(38,000,000)$ & 0 & $A$ \\
\hline 11 & Bleparoplasty & Skin necrosis & Deformity & Y & Y & $25,052(30,000,000)$ & 0 & A \\
\hline 12 & Augmentation rhinoplasty & Deformity & - & Y & Y & $25,052(30,000,000)$ & 0 & $A$ \\
\hline 13 & Facial contouring surgery & Deformity & Infection & Y & Y & $21,711 \quad(26,000,000)$ & 0 & A \\
\hline 14 & Facial contouring surgery & Deformity & Sensory change & Y & Y & $24,217(29,000,000)$ & 0 & $A$ \\
\hline 15 & Facial contouring surgery & Deformity & Sensory change & Y & Y & $25,052(30,000,000)$ & 0 & A \\
\hline 16 & Body contouring surgery & Deformity & Scar & Y & Y & $23,382(28,000,000)$ & 0 & $A$ \\
\hline 17 & Body contouring surgery & Deformity & Scar & Y & Y & $22,546(27,000,000)$ & 0 & A \\
\hline 18 & Body contouring surgery & Deformity & & Y & Y & $3,423(4,100,000)$ & 0 & $A$ \\
\hline
\end{tabular}

Y, effective; A, the settlement agreement was prepared in detail, including matters concerning the side effects of surgery, potential problems, and negligence by the doctor; B, it was difficult to deem that the doctor was liable based solely on a negative outcome of surgery in addition to: (i) the difficulty of the procedure and (ii) the prior consent given for repeated surgery that was recognized.

a)Unit, US dollar (South Korean Won); average amount, currency as of January 25, 2016.

which had ineffective settlements. There was no statistically significant correlation between geographical area and the effectiveness of settlements $(\mathrm{P}=0.865)$ (Table 2$)$.

\section{Factors used to determine whether the settlement was effective}

When the effectiveness of the settlement agreement was not recognized, the case was sent to a civil court in South Korea to seek judgment on their merits and to determine whether there was negligence on the part of the doctor in providing medical treatment. In the South Korean legal system, this type of litigation is classified as a damage compensation lawsuit. In the civil court, there is no jury, and a judge makes a decision after the hearings of both parties (Table 3 ). 


\section{Fig. 5. Geographical distribution of population, plastic surgeons, precedents}

Geographical distribution of the total population, number of plastic surgeons, and court precedents. Precedents that were recognized as effective by the court are marked as "effective," and those that were not recognized by the court are marked as "ineffective." Fifty-four percent of total plastic surgeons were working in the capital city of Seoul, and 12\% of total plastic surgeons were working in Gyeonggi-do, the most populated state in South Korea.

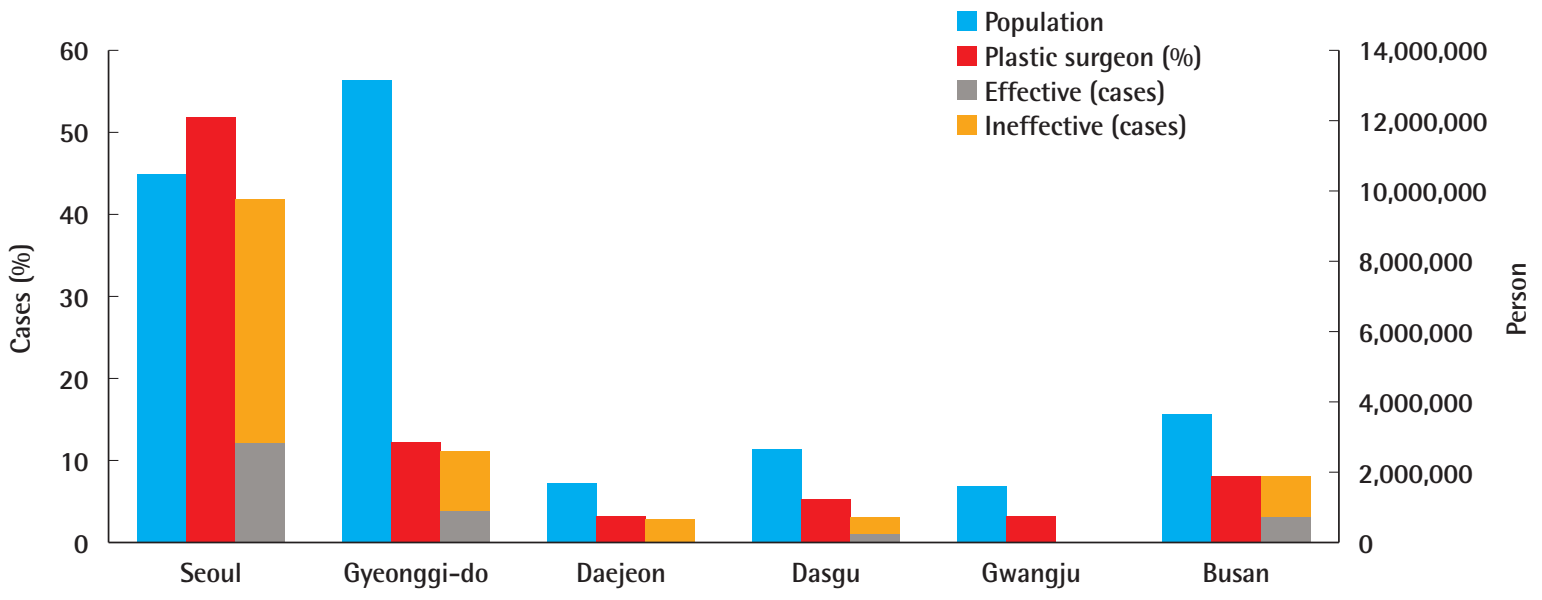

Table 2. The geographical distribution of precedent cases

\begin{tabular}{|c|c|c|c|c|c|c|c|c|}
\hline \multirow{2}{*}{ City } & \multicolumn{2}{|c|}{ Population } & \multicolumn{2}{|c|}{ Settlement } & \multirow{2}{*}{ Total } & \multirow{2}{*}{\multicolumn{3}{|c|}{ P-value }} \\
\hline & Total & Plastic surgeons & Effective & Ineffective & & & & \\
\hline Seoul & $10,022,181$ & 1,196 & 12 & 30 & 42 & $0.865^{a)}$ & $0.999^{b)}$ & $0.685^{c)}$ \\
\hline Gyeonggido & $12,522,606$ & 274 & 4 & 8 & 12 & & & \\
\hline Daejeon & $1,518,775$ & 62 & 0 & 3 & 3 & & & \\
\hline Daegu & $2,487,829$ & 119 & 1 & 2 & 3 & & & \\
\hline Gwangju & $1,472,199$ & 57 & 0 & 0 & 0 & & & \\
\hline Busan & $3,364,702$ & 166 & 3 & 5 & 8 & & & \\
\hline
\end{tabular}

${ }^{a}$ The effectiveness of settlement agreements and geographical area did not have a statistically significant correlation (Fisher exact test, $\mathrm{P}=0865$ ); ${ }^{\text {bT } T h e ~ g e o g r a p h i c a l ~}$ population distribution and the number of precedent cases did not have a statistically significant correlation (Fisher exact test, $\mathrm{P}=0.999$ ); ${ }^{\circ}$ The geographical distribution of plastic surgeons and the number of precedent cases did not have a statistically significant correlation (Fisher exact test, $\mathrm{P}=0.685$ ).

Table 3. Fisher exact test results for the relationship between the timing of the settlement and its effectiveness

\begin{tabular}{|lrcrlr}
\hline \multirow{2}{*}{ Settlement timing } & \multicolumn{2}{c}{ Settlement } & & \\
\cline { 2 - 3 } & Effective & Ineffective & & P-value \\
\hline Preoperational & 0 & 0 & 0 & 0.602 \\
Before patient fully healed & 16 & 47 & 63 & \\
After patient fully healed & 2 & 3 & 5 & \\
\hline
\end{tabular}

The Fisher exact test results showed that the P-value (0.602) exceeded the level of significance $(0.05)$, so there was no statistically significant correlation between the timing of the settlement and its effectiveness.

The following factors were considered when judging whether the covenant not to sue between the patient and the doctor was effective: (1) the parties involved, (2) whether the settlement was prepared with specific details, (3) whether sufficient information on the patient's own current status was provided to the patient, and (4) whether the damages incurred were ultimately predictable at the time of the settlement. A settlement agreement was deemed legally effective if the doctor had explained the settlement to the patient at the time of preparation, had included specific details, and had obtained the signature of the patient.

\section{The timing of the settlement and its effectiveness}

The timing of the settlement played an important role in determining the outcome for the physician. We classified the timing of a settlement as preoperational, before the patient had fully healed, and after the patient had fully healed. There were no cases of preoperational settlement, 63 cases of a settlement before the patient had fully healed ( 16 effective settlements and 47 ineffective settlements), and 5 cases of a settlement after the patient had fully healed ( 2 effective settlements and 3 ineffective 
Table 4. Indemnification amounts for the court precedents in which the settlement agreement was not recognized as effective

\begin{tabular}{|c|c|c|c|c|}
\hline Procedure & Claimed amount & Indemnification amount & Damage compensation & Consolation \\
\hline Augmentation mammoplasty & $\$ 68,353.36(\$ 81,853,142.88)$ & $\$ 15,101.22(W 18,083,713.72)$ & $\$ 9,104.23(\forall 10,902,318.37)$ & $\$ 5,996.99(\$ 7,181,395.35)$ \\
\hline Face rejuvenation & $\$ 67,623.64(\forall 80,979,304.05)$ & $\$ 14,776.18(W 17,694,471.02)$ & $\$ 9,012.23(\forall 10,792,145.44)$ & $\$ 5,763.95(W 6,902,325.58)$ \\
\hline Facial contouring surgery & $\$ 55,360.03(\nVdash 66,293,636.36)$ & $\$ 18,640.23(W 22,321,676.00)$ & $\$ 7,799.46$ (廿9,339,857.82) & $\$ 10,840.77(\nVdash 12,981,818.18)$ \\
\hline Body contouring surgery & $\$ 65,701.69(W 78,677,777.78)$ & $\$ 11,847.83(W 14,187,777.78)$ & $\$ 8,702.39(W 10,421,111.11)$ & $\$ 3145.44(W 3,766,666.67)$ \\
\hline
\end{tabular}

Unit, US dollar (South Korean Won); average amount, currency as of January 25, 2016.

Indemnification amount, damage compensation+consolation; Damage compensation (property damages), income losses+medical expenses paid+future medical expenses.

\section{Fig. 6. Payout distribution by type of procedure}

Unit, South Korean Won (KRW). Average amount.

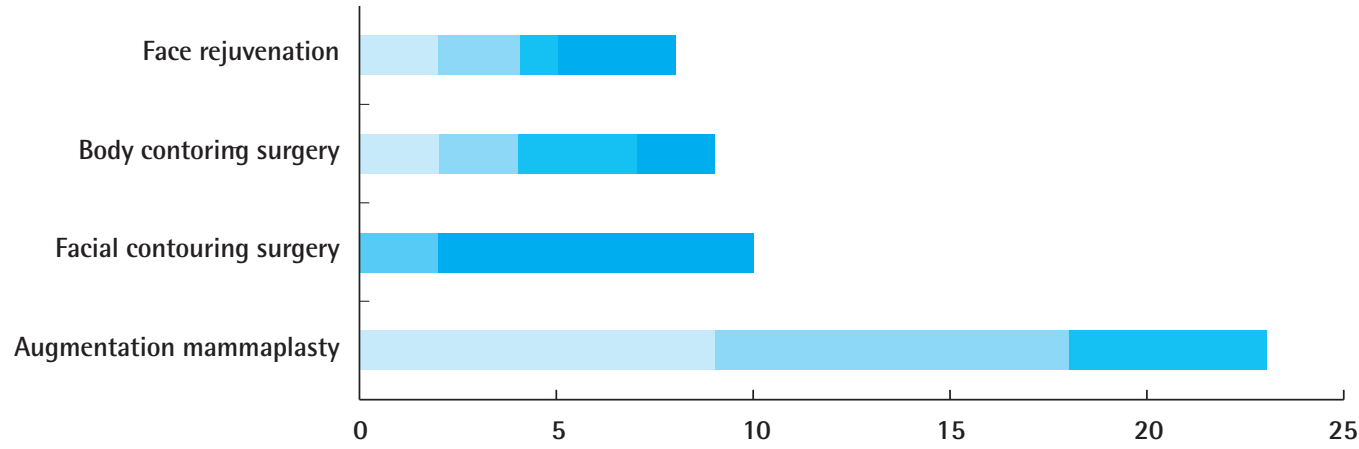

A: Invalid as a juristic act due to lack of fairness as a result of the plaintiff's strained circumstances, rashness, and inexperience

B: The fact of settlement is recognized, but the settlement may not be deemed to include the scope of the medical accident at issue

$\square$ C: The settlement was not made between the parties concerned and the settlement was recognized only to the extent of damages predictable at the time of settlement

D: The settlement does not cover medical accidents attributable to the defendant

E: The settlement was poorly prepared, lacking contents

settlements). There was no statistically significant correlation between the effectiveness and the timing of settlements $(\mathrm{P}=$ 0.602) (Table 4).

\section{The economic impact of effective and ineffective settlements}

In cases where settlement agreements were not recognized and negligence on the part of the doctor in providing medical treatment was found, the payment of indemnification was an average of USD 19,521.14 (KRW 23,376,563 as of January 25, 2016). The highest indemnification paid by a doctor was USD $18,640.23$ (KRW 22,321,676 as of January 25, 2016) for a facial contouring surgery case, and the lowest indemnification paid by a doctor was USD11,847.83 (KRW 14,187,778 as of January $25,2016)$ for a body contouring surgery case. In addition, in one case where the patient and the physician had agreed not to hold the hospital liable for the occurrence of any complications, the physician ultimately paid damages in compensation to the patient (Fig. 6).

\section{DISCUSSION}

In medical malpractice litigation in South Korea, the patient bears the burden of proof in demonstrating that negligence on the part of the doctor caused damage. It is also the patient's responsibility to prove that the damage was caused illegally, which is not easy. Moreover, when a medical accident occurs that is beyond the control of the doctor, a court may nevertheless render a decision that is unfair and that unfavorably acknowledges the doctor's negligence on the basis of the legal principle of factual presumption. It is difficult to make a judgment on a medical malpractice case. Thus, the reliability of court judgments is sometimes questioned [8]. Furthermore, filing a lawsuit is not an attractive solution for either party because prolonged litigation may cause both parties to suffer mental and physical exhaustion in addition to high litigation costs [9]. Various alternative dispute resolution systems have been introduced to address this problem. However, these systems require time for application and mediation procedures to take place and are limited in satisfying the interests of both parties [10]. Therefore, the most 
desirable way for resolving a dispute that arises from a medical accident is through an amicable settlement between the parties, rather than through a medical dispute mediation system.

Plastic surgeons perform cosmetic surgery more often than they treat diseases [11]. They, therefore, face relatively more complaints from patients about surgery-related matters than those in other medical departments $[12,13]$. However, unlike other medical practices, cosmetic surgery is often not suitable for medical litigation, as discrepancies commonly exist between a patient's personal feelings about beauty and a third party's view as to the results of the cosmetic surgery. There is also often nothing to be gained by filing a lawsuit because of the small indemnification amount. Moreover, it is not always guaranteed that a patient will win a lawsuit because a negative surgical outcome does not always indicate medical malfeasance. Therefore, when a dispute arises, the parties should first try to reach a settlement before taking legal action. In other words, when a dispute arises from a negative surgical outcome, the parties should first attempt to find a compromise and to end the dispute early, mainly by focusing on the negative outcome without inquiring into its exact cause or the existence of negligence. A hospital may occasionally predict a clear causal relationship between a medical treatment and a negative outcome, to which it admits its fault and seeks a settlement. A hospital may even seek a settlement when a causal relationship is not clearly recognized in order to avoid damages from a dispute with the patient. In this case, the parties prepare a settlement agreement according to the patient's covenant not to subject the hospital to civil and criminal liabilities as long as the hospital pays the patient in the form of settlement money, a refund of medical expenses, repeat surgery expenses, or paid medical expenses.

While the covenant not to sue is not recognized in administrative litigation, it is still effective in general civil litigation in South Korea. Nonetheless, notwithstanding the covenant not to sue, there are still many cases of litigation brought on by one of the parties. Any lawsuit filed in violation of a covenant not to sue is, in principle, subject to dismissal by reason of having no merit in the claim for protection of rights [14]. However, a covenant not to sue does not always turn out to be effective. The covenant not to sue is also a kind of contract, and it, therefore, should be effective. The covenant not to sue is frequently executed in South Korea in the field of plastic surgery, thus, this study examined relevant court precedents in order to review what requirements must be satisfied to ensure that the covenant not to sue is effective.

Court precedents that were subject to this study showed that the covenant not to sue was prevalent in every field of cosmetic plastic surgery. Patients and doctors generally entered into a set- tlement agreement in order to settle a dispute early that arose from a negative surgical outcome, regardless of medical negligence. Courts did not presume medical negligence based on the existence of a settlement agreement, and medical negligence was not recognized in court cases when the effectiveness of the settlement agreement was denied. In other words, a settlement agreement may be advantageous to a doctor insofar as the preparation of the settlement agreement alone does not provide a basis for finding medical negligence. Furthermore, if the effectiveness of the settlement agreement is recognized, the doctor is not liable for any additional payments other than settlement money upon occurrence of additional damages.

In order for a covenant not to sue to be established effectively in a Korean civil court, it is generally required (1) to be within the scope of rights that can be freely exercised by the parties, (2) to be reached by fair methods, (3) to apply to a situation or circumstance that is predictable by each party at the time of settlement, and (4) to be limited to a specific relationship between rights and obligations (any overbroad settlement clause is invalid). Once the covenant not to sue satisfies the foregoing requirements, it comes under strong protection [15]. The court precedents of the cosmetic surgery cases in this study showed that even when the covenant not to sue was executed, the doctors bore additional liabilities because the effectiveness of the covenant was not recognized due to its failure in satisfying the foregoing requirements.

If the covenant not to sue itself has no problems in terms of its contents, its effectiveness may be denied if either of the parties are deemed unqualified. In other words, the covenant not to sue is deemed to have been effectively executed only if it was reached within the scope of rights freely exercised by the parties. Therefore, any covenant not to sue that is executed on behalf of a patient by a third party with no rights is invalid. In one case where a doctor and the guardian of a patient (the patient's husband) had entered into a settlement agreement, the court dismissed the doctor's motion that was based on the covenant not to sue on the grounds that the covenant at issue was not effective for the patient since it had not been prepared by the patient herself and that there was no justifiable reason to believe that the patient's husband had the power of representation [16]. It is, therefore, desirable for a doctor to enter into a settlement agreement with a patient directly, and if the doctor must inevitably enter into an agreement with the patient's family or any other third party, it is advisable for the doctor to check a representation agreement in order to confirm proper entrustment of the power of representation.

There were cases where the covenant itself was found to have been executed unfairly. In one case, the doctor had explained 
that the inflammation and skin necrosis that were occurring after augmentation mammaplasty were caused by the patient's smoking. Furthermore, the doctor coerced the patient into preparing and signing a letter of apology and a letter of waiver before treating the complications, threatening that treatment would be withheld until the patient signed the letter of waiver. In this circumstance, the court ruled the covenant to be invalid pursuant to Article 104 of the Civil Act of South Korea, deeming that it constituted a juristic act that had conspicuously lost fairness through the strained circumstances, rashness, and inexperience of the plaintiff [17]. A doctor should not lay the fault of any post-surgery side effects or negative outcomes on a patient by taking advantage of the patient's ignorance. If a negative outcome can be partly attributed to a patient, the doctor should draw up a settlement agreement that reflects the relevant liability of the patient.

Furthermore, the covenant not to sue is effective only when it applies to a situation or circumstance that is predictable at the time of the agreement. This indicates that the covenant not to sue may lose its effectiveness with respect to unpredictable circumstances. In one case where a patient suffered from skin necrosis after a filler injection, the court recognized a severe discrepancy between the damage that was anticipated at the time of entering into the settlement agreement and the amount of actual damage following the surgery. The patient entered into the agreement with the expectation of only a slight scar but ended up losing both nostrils. In other words, if the patient enters into a settlement agreeing to accept an insufficient compensation proposed by the doctor because it was difficult for the patient to ascertain the actual extent of the damages, the settlement agreement is no longer applicable for any unpredictable extra damage occurring after the settlement. It is, therefore, advisable for doctors to propose compensation after the damage is partially or fully fixed, rather than proposing compensation before the damage is fixed and only under consideration of minimizing the settlement amount and bringing the dispute to an early resolution. Doctors must accordingly provide an adequate explanation to their patients about the potential complications at the time of the settlement [18].

The court precedents in this study showed that there were no attorneys involved during the settlement process. Higher rates of settlements would unquestionably be recognized by the courts if attorneys were involved with the patients' claims against the covenant not to sue during the settlement. However, there is a high attorney fee for involving an attorney during the settlement process, and, thus, its cost-effectiveness should be further evaluated. Moreover, the involvement of an attorney in the settlement process differs between South Korea and the
United States due to the cultural commitment to Confucianism in Korea. A successful settlement might also be difficult to reach when involving an attorney, as patients generally believe that doctors are attempting to hide malfeasance when they choose to involve an attorney in the settlement process.

There are 22 million people in the Seoul metropolitan area, equaling roughly half of South Korea's total population (the area of South Korea is 99,720 square kilometers, smaller than the state of Ohio in the United States). Likewise, $66 \%$ of all plastic surgeons work in the Seoul metropolitan area and 54 precedents (79\%) in this study occurred in this region. The effectiveness of settlements was not found to have a statistically significant association with the distribution of plastic surgeons $(\mathrm{P}=0.685)$ or the distribution of the population $(\mathrm{P}=0.999)$. Moreover, there was no statistically significant association between geographical area and the effectiveness of settlements $(P=0.865)$. In other words, the effectiveness of a settlement relies on a fair process and the fulfillment of the aforementioned requirements.

The timing of a settlement may be of interest to the physician. We found that there was no meaningful statistical relationship between the timing of a settlement and its effectiveness ( $\mathrm{P}=$ 0.602). Most settlements in this study (93\%, 63 cases) occurred before the patient fully healed, as settlements usually concern resolving a problem that develops after primary surgical/nonsurgical procedures through monetary and physical compensation. This also explains why the most important factor of a settlement agreement is a fair and just process.

We found another interesting result in this study. The settlement for fee-free reoperations and covenant not to sue was a generic type of settlement. However, the relationship between a fee-free reoperation and the compensation amount was not statistically significant $(P=0.857)$ when the settlement was not recognized by the court. One might believe that having a feefree reoperation prior to a medical litigation would be considered by the court in determining the compensation amount. However, this was not the case. The surgeon should understand that a fee-free reoperation is neither mandatory nor an economically sound decision. This result also suggests that doctors should settle thoroughly, as it is a better economic strategy.

A settlement agreement is merely a means of stating the explicit intentions of both parties. Its contents are of paramount importance and they must be legitimate and as specific as possible. A settlement agreement that contains terms that are unclear or sets in motion an ambiguous compensation plan may lead to a legal dispute later. As an example, a statement that the doctor will assume liability for the payment of all medical expenses or for all repercussions of a procedure is not clear and may allow the patient to adopt a different point of view later on. This can 
consequently renew a dispute. In one of the court cases in this study, the doctor obtained the signature of a patient for the statement "the patient will not hold the hospital liable for any abnormality occurring during the procedure" on the medical records. The civil court in South Korea did not acknowledge the effectiveness of this covenant on the basis that the statement was too broad and was not an adequately concrete agreement. Therefore, when preparing a settlement agreement, it is advisable to review the contents thereof, rather than to take the preparation of a settlement agreement per se as legally meaningful. Parties must prepare a legally binding settlement agreement. Therefore, they should be careful not to execute any settlement agreement that is legally meaningless, which is just a waste of paper.

In conclusion, doctors that are drafting a settlement agreement to end a medical dispute should keep in mind the following considerations. First, a settlement should be made with the counterparty to the dispute. If that is not possible, a lawfully authorized agent should be involved. Second, it is prohibited to fault the patient without revealing any medical malpractice and to induce the patient to enter into a disadvantageous settlement. Third, the scope of the settlement should be limited to complications that can reasonably be predicted at the time of drafting the settlement agreement. This means that doctors should readily take sole responsibility for any unpredicted complications that occur after the settlement, as they fall outside the scope of the settlement. Lastly, doctors should avoid encouraging patients to enter into a settlement in order to end their relationship. They should also assert that early prevention of a dispute is necessary, even if complications have not yet been addressed with the patient. Patients generally decide to initiate litigation against their doctor in violation of the covenant not to sue not simply because a complication has occurred, but mainly because they have lost confidence in their doctor. If malpractice by a doctor occurs, the doctor should share the matter with the patient, apologize, and try to amicably resolve the dispute with the patient. If a doctor is blamed unfairly for a patient's late recovery despite his or her best efforts, it is important that the doctor continue to maintain communications with the patient and preserve the confidence of the patient. Nevertheless, medical disputes may arise. After experiencing a single medical dispute, doctors tend to feel intimidated when treating patients, and it may take time to regain self-confidence. Lack of basic knowledge of the law may increase the likelihood of medical disputes. Therefore, doctors should acquire a basic knowledge of the law in order to prevent medical disputes and to treat patients confidently.

\section{ORCID}

Jung Woo Kwon https://orcid.org/0000-0002-6629-369X

Bo Young Park https://orcid.org/0000-0003-4612-6672

So Ra Kang https://orcid.org/0000-0002-7074-8773

Seung Eun Hong https://orcid.org/0000-0002-2657-7428

\section{REFERENCES}

1. ISAPS international survey on aesthetic/cosmetic procedures performed in 2014, ISAPS glocal statistics [Internet]. Hanover, NH; International Society of Aesthetic Plastic Surgery; 2015 [cited 2016 Jan 24]. Available from: https:// www.isaps.org/Media/Default/global-statistics/2015\%20 ISAPS\%20Results.pdf.

2. Mavroforou A, Giannoukas A, Michalodimitrakis E. Medical litigation in cosmetic plastic surgery. Med Law 2004;23: 479-88.

3. Bal BS. An introduction to medical malpractice in the United States. Clin Orthop Relat Res 2009;467:339-47.

4. Im BH. Analysis of medical disputes precedent. J Korea Con Assoc 2010;10:294-303.

5. Min JH. Growth of Medical accident in plastic surgery, malpractice lawsuit arise rapidly [Internet]. Seoul: Dailymedi; 2014 [cited 2016 Jan 24]. Available from: http://dailymedi. $\mathrm{com} /$ news $/$ view.html?section $=1$ \& category $=3 \&$ no $=784922$.

6. Ministry of Governement Legislation. Korean Law in English: Civil procedure act [Internet]. Sejong; Korea Ministry of Government Legislation: 2017 [cite 2017 June 27]. Available from: https://www.moleg.go.kr/english/korLawEng;jsessionid=wKrWfIepiGLGz6kjuiUN4FA9tAor12VGMK MLHDaT7anlhV8fgunGbWeJm19zvQhv.moleg_a2_servlet_engine2?pstSeq=52676\&pageIndex=44.

7. Supreme Court of South Korea. Decision No. 2000 Da17803 (rendered 2002 Oct 11).

8. Korea Institute for Health and Social Affairs. Establishment of effective medical dispute mediation system. Health Soc Affairs Forum 1997;7:63-6.

9. Kim GR. A study on alternative medical disput resolution: with a focus on medical dispute mediation of kca. Korean Soc Law Med 2012;13:71-89.

10. Lee SY, Kim UJ, Lee SH, et al. Research paper on activating the medical accident damage relief and medical dispute mediation law. Korea Ins Health Soc Aff 2012;8:16-95.

11. Lyu SY, Liao CK, Chang KP, et al. Analysis of medical litigation among patients with medical disputes in cosmetic surgery in Taiwan. Aesthetic Plast Surg 2011;35:764-72.

12. Lee SS. Analysis of types of remedy for damages from medi- 
cal malpractice filed with Korea Consumer Agency: from the enforcement of the amended consumer protection act to the present. Med Policy Forum 2004;2:98-106

13. Marchesi A, Marchesi M, Fasulo FC, et al. Mammaplasties and medicolegal issues: 50 cases of litigation in aesthetic surgery of the breast. Aesthetic Plast Surg 2012;36:122-7.

14. Supreme Court of South Korea. Decision No. $96 \mathrm{Hu} 1743$ (rendered 1997 Sep 5).

15. Jang BH. Non-litigation agreement and its legal effects [Internet]. Seoul: Kukihealth; 2009 [cited 2016 Jan 24]. Available from: http://news.kmib.co.kr/article/view.asp?arcid=
1258107956.

16. Seoul Central District Court of South Korea. Decision No. 2010Gahap45185 (rendered 2012 June 5).

17. Seoul High Court of South Korea. Decision No. 2012 Na49348 (rendered 2013 June 27).

18. Jang BH. Non-litigation agreement and its legal effects [Internet]. Seoul: Monthly The Ophthalmic Information; 2001 [cited 2016 Jan 24]. Available from: http://eyeclinickorea.com $/ \mathrm{html} /$ board4/board/view.html?board_id= B4_6\&uid $=75 \&$ cline $=\& s o=\& s k=$. 